\title{
Serum interleukin- 6 in chronic obstructive pulmonary disease patients and its relation to severity and acute exacerbation
}

\author{
Fatma G. M. Hussein ${ }^{1}$, Randa S. Mohammed ${ }^{1}$, Rasha A. Khattab² and Laila A. Al-Sharawy ${ }^{1 *}$
}

\begin{abstract}
Background and objectives: The role of interleukins in the severity and clinical profile of chronic obstructive pulmonary disease (COPD) is not known, but evidence supports the contribution of systemic inflammation to disease pathophysiology. This study evaluated the relationship of serum interleukin-6 (IL-6) to the severity and clinical parameters of COPD.

Aim of work: The aim of the work is to estimate the level of IL-6 in COPD patients and its relation to COPD severity and acute exacerbation.

Patients and method: We analyzed 45 COPD patients and 45 normal population as control. We estimate the IL-6 level by ELISA and correlate it with the severity and frequency of COPD exacerbation.

Results: In the current study, we noticed that IL-6 level was high in COPD patients and in those who experience frequent exacerbation. Also, IL- 6 show a relation with the parameter of pulmonary function test; there is a statistically significant negative correlation with $p$-value $<0.05$ between the level of IL-6 and the forced expired volume in $1 \mathrm{~s} /$ forced vital capacity (EFV1/FVC) among cases with COPD, which indicated that decrease in EFV/FVC will associate with the increase in IL-6 level.

Conclusions: The study revealed that serum IL-6 level elevated with increasing severity of airflow limitation in COPD patients, particularly in acute exacerbation phase. This increase was associated with a reduced quality of life and increased severity of hypoxemia.
\end{abstract}

Keywords: COPD, ELISA, Interleukin-6, Pulmonary function

\section{Introduction}

COPD is a common, preventable, and treatable disease that is characterized by persistent respiratory symptoms and airflow limitation that is due to airway and/or alveolar abnormalities usually caused by significant exposure to noxious particles or gasses [1]. COPD is a major cause of chronic morbidity and mortality throughout the world; many people suffer from this disease for years and die

\footnotetext{
*Correspondence: lailaanwer2015@gmail.com

${ }^{1}$ Chest Diseases, Faculty of Medicine, Beni-Suef University, Beni-Suef,

Egypt

Full list of author information is available at the end of the article
}

from it or its complications. Globally, the COPD burden is projected to increase in the coming decades because of continued exposure to COPD risk factors and aging of the population [2].

Individuals with COPD had significantly raised levels of several markers of inflammation including C-reactive protein (CRP), fibrinogen, activated leucocytes, and TNF $\alpha$, confirming the presence of systemic inflammation [3]. Since 2001, according to the Global Initiative for Chronic Obstructive Lung Disease (GOLD) guideline, patients with stable COPD have been classified as mild, moderate, severe, and extremely severe depending on lung function. The 2011 GOLD guideline has been 
revised to divide patients with COPD into grades $\mathrm{A}, \mathrm{B}$, $\mathrm{C}$, and $\mathrm{D}$. This classification method has been improved several times and is still in use today, which is based on lung function, frequency of acute exacerbations, symptom scores, and risk factors [1].

Interleukin (IL)-6 is a pleotropic cytokine that acts as a pro-inflammatory mediator and acute phase response inducer but has also been reported to have anti-inflammatory properties. While largely associated with T-cells and macrophages, it is increasingly apparent that the airway epithelium is a major source of IL-6 in the lungs. In its anti-inflammatory role, IL-6 has inhibitory effects on tumor necrosis factor- $\alpha$ and IL-1. Moreover, it has been implicated in the synthesis of prostaglandin $E_{2}$. IL- 6 is produced downstream from the recognition of microbial- and damage-associated molecular patterns by pattern recognition receptors of the innate immune system [4]. Thus, the aim of this study is to estimate the level of IL-6 in COPD patients and its relation to COPD severity and acute exacerbation.

\section{Methods}

\section{Study population}

This case-control study was carried out in Beni Suef University Hospital between March 2020 and November 2020. The study group was consisting of COPD patients according to the GOLD 2019 classification criteria. The study includes 90 subjects.

The subjects were divided into two groups:

Group A: 45 patients with COPD. The diagnosis of COPD is based on spirometry according to GOLD guidelines 2019.

Group B: 45 apparently healthy subjects as controls who were not COPD.

The patients were enrolled in this study from the Respiratory Outpatient Clinic and Inpatient Respiratory Department.

\section{Inclusion criterion}

The inclusion criterion is all patients aged $>40$ years and $<80$ years, of both genders, who were diagnosed to have COPD according to the GOLD 2019 by spirometry and given the consent for participation in the study.

\section{Exclusion criteria}

The following are the exclusion criteria:

1. Any patient with systemic inflammation as bronchial asthma or rheumatoid arthritis.

2. A detailed clinical history was carried out for every patient. In the clinical history, the duration of COPD with a history of exacerbation and treatment will be elicited. A history of the presence of risk factors such as smoking, exposure to fumes (biomass), and the presence of any other chronic disease was inquired.

3. Thereafter, the detailed physical examination also had been carried out.

4. Pulmonary function test was performed by master screen no.: 781040 (care fusion). Measurements were obtained for FVC, FEV1, ratio between them, PEF, $\mathrm{FEF}_{25 \%}, \mathrm{FEF}_{50 \%}$, and $\mathrm{FEF}_{75 \%}$ (the readings for FEV1 and ratio were the ones included in the statistical analysis as indices for obstructive pattern of respiration).

5. Labs including complete blood count, urea, and serum creatinine. ESR was done for all patients.

6. Exercise capacity by the 6-min walk test.

7. Dyspnea score by MMRC score.

8. Health state assessment by CAT score.

9. Arterial blood gas analysis to define patients with respiratory failure.

10. Determination of IL-6 serum levels by sandwich enzyme-linked immunosorbent assay (ELISA). The detection range is $0.2-8 \mathrm{ng} / \mathrm{L}$.

\section{Statistical analysis}

Data were collected and coded to facilitate data manipulation and double entered into Microsoft Access and data analysis performed using the Statistical Package of Social Science (SPSS) software version 22 in Windows 7. Simple descriptive analysis was in the form of numbers and percentages of qualitative data, arithmetic means as central tendency measurement, and standard deviations as a measure of dispersion of quantitative parametric data. Quantitative data included in the study first tested for normality by one-sample Kolmogorov-Smirnov test in each study group then inferential statistic tests selected.

For quantitative parametric data:

1. The independent samples $t$ test was used to compare the quantitative measures between two independent groups.

For quantitative non parametric data:

1. The Mann-Whitney test was used to compare two independent groups.

For qualitative data:

1. The chi-square test was used to compare between two of more than two qualitative groups. 
Table 1 Demographic features of 45 patients and 45 controls under study

\begin{tabular}{|c|c|c|c|c|}
\hline & Group $1(n=45)$ & Group $2(n=45)$ & $P$-value & Sig. \\
\hline \multicolumn{5}{|l|}{ Sex } \\
\hline Male & 31 (68.9\%) & $26(57.8 \%)$ & 0.4 & NS \\
\hline Female & $14(31.1 \%)$ & $19(42.2 \%)$ & & \\
\hline \multicolumn{5}{|l|}{ Age } \\
\hline Range & $50-78$ & $51-75$ & 0.5 & NS \\
\hline Mean \pm SD & $61.2 \pm 7.1$ & $62.1 \pm 7.2$ & & \\
\hline \multicolumn{5}{|l|}{ Residence } \\
\hline Rural & $18(40 \%)$ & $28(62.2 \%)$ & 0.06 & NS \\
\hline Urban & $27(60 \%)$ & $17(37.8 \%)$ & & \\
\hline \multicolumn{5}{|c|}{ Exposure to biomass } \\
\hline Yes & $33(73.3 \%)$ & $32(71.1 \%)$ & 0.9 & NS \\
\hline No & $12(26.7 \%)$ & 13 (28.9\%) & & \\
\hline \multicolumn{5}{|l|}{ Smoking } \\
\hline Smoker & $29(64.4 \%)$ & 27 (60\%) & 0.8 & NS \\
\hline Non-smoker & $16(35.6 \%)$ & $18(40 \%)$ & & \\
\hline \multicolumn{5}{|l|}{ Smoking index } \\
\hline Mean/SD & $385.3(359.2)$ & $228.8(269.9)$ & 0.05 & S \\
\hline \multicolumn{5}{|c|}{ Exacerbation frequency } \\
\hline Yes & $22(48.9 \%)$ & & & \\
\hline No & $23(51.1 \%)$ & & & \\
\hline \multicolumn{5}{|c|}{ Respiratory failure } \\
\hline Yes & $18(40 \%)$ & & & \\
\hline No & $27(60 \%)$ & & & \\
\hline
\end{tabular}

2. The bivariate Pearson correlation test was used to test the association between variables.

3. A $p$-value $<0.05$ was considered as statistical significant.

\section{Results}

The study was conducted on 45 COPD patients and 45 control subjects. The demographic features of the studied groups were shown in Table 1; most of the patients were at age ranging from 50 to 78 with a mean of 61.2 \pm 7.1 years with male predominance $(68.9 \%)$. The control patients in the group were in the six decade of their life with a mean of $62.1 \pm 7.5$ years; $57.8 \%$ were males, and $42.2 \%$ were females. Also, the table illustrates that there was no statistical significance difference between cases and controls as regards demographic characters (age and sex) with a $p$-value $>0.05$.

The table illustrates that there was no statistical significance difference between cases and controls as regards medical history (residence, smoking, and exposure to biomass) with a $p$-value $>0.05$. On the other hand, there was a statistical significant higher mean of smoking index among COPD cases with a $p$-value $<0.05$ (Fig. 1).

Table 2 illustrates that there was no statistical significance difference between cases and controls as regards TLC with a $p$-value $>0.05$. On the other hand, there was a statistical significant higher mean of IL-6 level among COPD cases with a $p$-value $<0.05$. Table 1 illustrates that

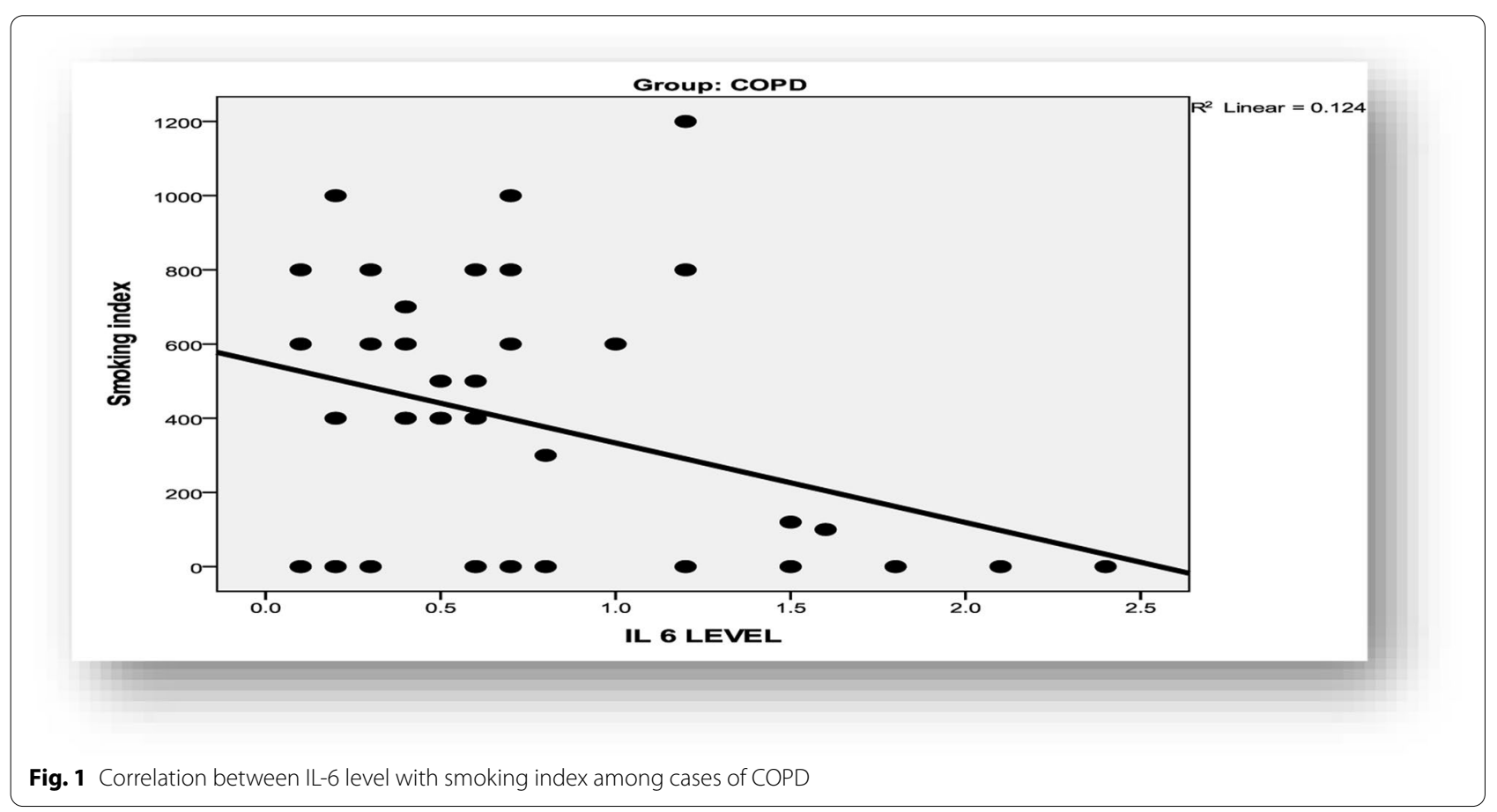


Table 2 Comparisons of laboratory investigations, pulmonary function test parameters, and different variables in different study groups

\begin{tabular}{|c|c|c|c|c|c|c|}
\hline \multirow[t]{2}{*}{ Variables } & \multicolumn{2}{|c|}{ Cases $(N=45)$} & \multicolumn{2}{|c|}{ Control $(N=45)$} & \multirow[t]{2}{*}{$P$-value } & \multirow[t]{2}{*}{ Sig. } \\
\hline & Mean & SD & Mean & SD & & \\
\hline $\mathrm{TLC}$ & 7931.1 & 2518.5 & 7075.6 & 2036.3 & 0.08 & NS \\
\hline IL6 & 0.76 & 0.59 & 0.23 & 0.25 & $<0.001$ & $\mathrm{HS}$ \\
\hline FVC & 54.02 & 10.4 & 103.9 & 12.6 & $<0.001$ & $\mathrm{HS}$ \\
\hline FEV1 & 33.8 & 7.9 & 91.5 & 12.9 & $<0.001$ & $\mathrm{HS}$ \\
\hline FEV/FVC & 55.3 & 10.6 & 87.6 & 5.9 & $<0.001$ & $\mathrm{HS}$ \\
\hline FEF $25-75$ & 16.4 & 6.8 & 93 & 8.7 & $<0.001$ & $\mathrm{HS}$ \\
\hline ESR & 20.8 & 12.9 & & & & \\
\hline CAT score & 17.6 & 5.3 & & & & \\
\hline MMRC & 2.4 & 0.96 & & & & \\
\hline Six-minute walk test & 292.1 & 110 & & & & \\
\hline
\end{tabular}

among COPD cases, $48.9 \%$ had exacerbation frequency and $51.1 \%$ show no exacerbation. Also, patients with respiratory failure were $40 \%$ which is usually defined by an arterial oxygen tension of less than $60 \mathrm{mmHg}(<8.0$ $\mathrm{kpa})$ and/or an arterial carbon dioxide tension $\left(\mathrm{PaCO}_{2}\right)$ greater than $45 \mathrm{mmHg}$ [5].

Table 2 also illustrates that there was a statistically significant difference between cases and controls as regards respiratory function tests (FVC, FEV1, and FEV1/FVC level) with a $p$-value $<0.05$ with low mean respiratory function among cases of COPD.

Table 2 illustrates that the mean ESR among cases was $20.8 \pm 12.9$, and the mean FEF $25-75 \%$ was $16.4 \pm 6.8$; as regards CAT score, the mean was $17.6 \pm 5.3$, and MMRC was $2.4 \pm 0.96$; and, finally, for the 6 -min walk test, the mean was $292.1 \pm 110$.

Table 3 illustrates that there was no statistically significant difference in the mean level of IL- 6 between different medical histories as hypoxia on admission, smoking, and exposure to biomass with a $p$-value $>0.05$. On the other hand, there was a statistically significant higher mean of IL-6 level among COPD cases who show exacerbation frequency with a $p$-value $<0.05$. Table 3 illustrates that there is a statistically significant negative correlation with a $p$-value $<0.05$ between the level of IL- 6 and smoking index among cases with COPD, which indicated that the decrease in smoking index will associate with the increase in IL-6 level. On the other hand, there is no statistically significant correlation with a $p$-value $>0.05$ between IL- 6 level with age and other laboratory investigations.

Figure 2 illustrates that there is a statistically significant negative correlation with a $p$-value $<0.05$ between the level of IL-6 and EFV/FVC among cases with COPD, which indicated that the decrease in EFV/FVC
Table 3 Comparisons of IL-6 level in different medical history among cases with COPD

\begin{tabular}{lllll}
\hline Variables $(\boldsymbol{N}=\mathbf{4 5})$ & \multicolumn{1}{l}{ IL-6 level } & & P-value & Sig. \\
\cline { 2 - 3 } & Mean & SD & & \\
\hline $\begin{array}{l}\text { Hypoxia on admission } \\
\text { Yes }\end{array}$ & 0.733 & 0.62 & 0.8 & NS \\
No & 0.774 & 0.57 & & NS \\
Exposure to biomass & & & & \\
$\quad$ Yes & 0.788 & 0.58 & 0.6 & NS \\
No & 0.675 & 0.62 & & \\
Smoking & & & & \\
Smoker & 0.631 & 0.42 & 0.06 & HS \\
Non-smoker & 0.988 & 0.77 & & \\
Exacerbation frequency & & & & \\
Yes & 1.19 & 0.54 & $<001$ & \\
No & 0.339 & 0.19 & & \\
\hline
\end{tabular}

will associate with the increase in IL-6 level. On the other hand, there is no statistically significant correlation with a $p$-value $>0.05$ between IL-6 level with age and other laboratory investigations. Figure 3 illustrates that there is a statistically significant negative correlation with a $p$-value $<0.05$ between the level of IL- 6 and each of FEF $25-75 \%$ and 6-min walk test among cases with COPD, which indicated that the decrease in FEF $25-75 \%$ and 6-min walk test will associate with the increase in IL-6 level. Also, there is a statistically significant positive correlation with a $p$-value $<0.05$ between the level of IL- 6 and each of CAT score and MMRC among cases with COPD, which indicated that the decrease in CAT score and MMRC will associate with the decrease in IL-6 level (Figs. 4, 5, and 6). On the 


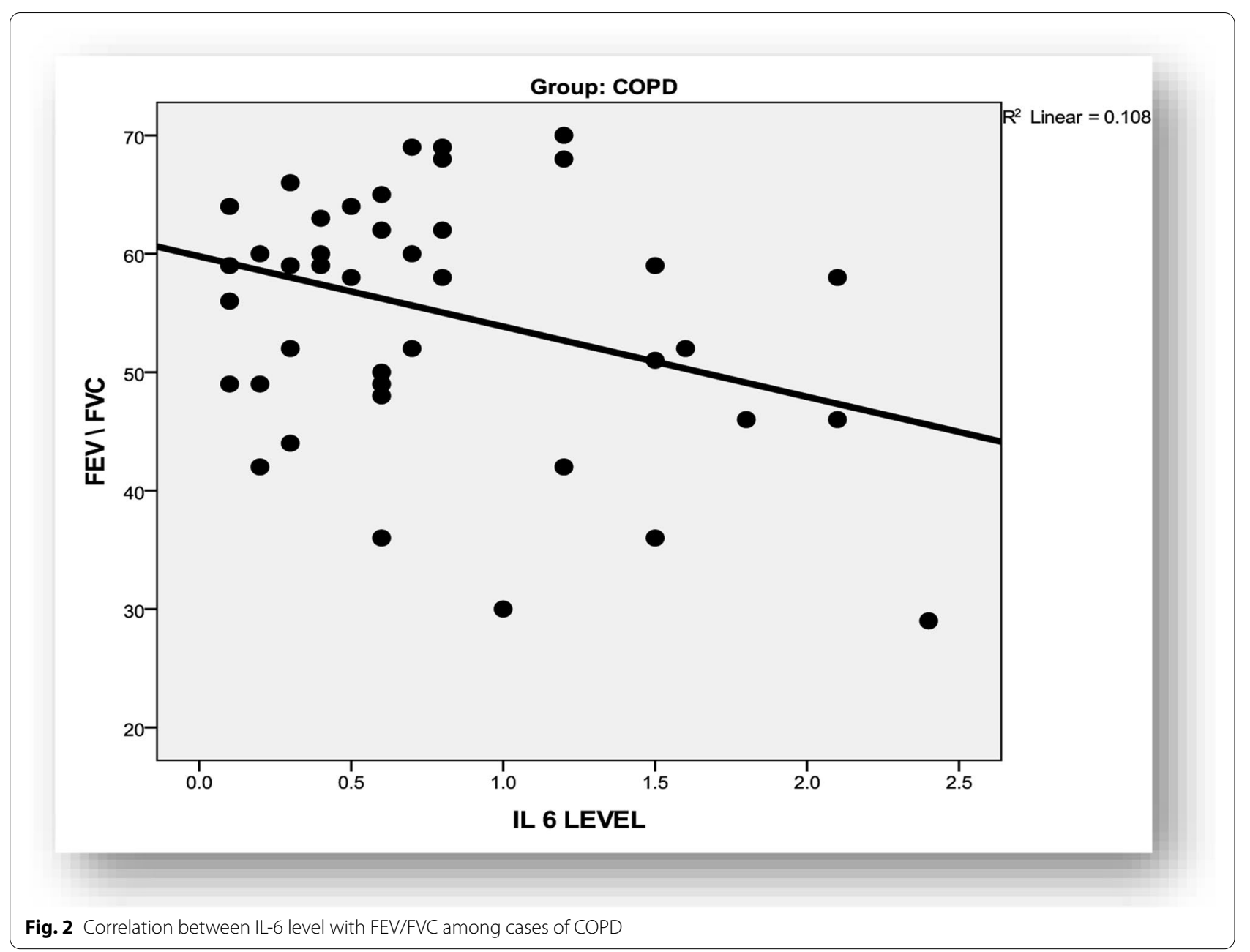

other hand, there is no statistically significant correlation with a $p$-value $>0.05$ between IL- 6 level with ESR.

\section{Discussion}

COPD is characterized by an intense inflammatory process in the airways, parenchyma, and pulmonary vasculature. Chronic inflammation leads to fixed narrowing of small airways and alveolar wall destruction (emphysema) [6]. Further studies have found that the inflammatory response not only existed in the airway and lung itself [7], but also in the systemic circulatory system [8]. Moreover, the systemic inflammatory response in acute exacerbation phase is significantly enhanced, and the production of TNF- $\alpha$, interleukin-type (IL-6, IL-8), CRP, and other inflammatory cytokines increases in the circulatory system [9].

IL-6 is a crucial cytokine, which can produce a variety of acute phase proteins when it acts on liver cells
[10]. Some observational studies indicated the IL-6 levels were significantly elevated in the peripheral blood of patients with COPD, and it was associated with FEV1 [11]. However, other studies [12] showed no statistical significance. Therefore, we performed this case-control study that included 45 COPD patients and 45 normal persons, to examine the associations between IL- 6 levels and stable COPD.

The aim of this study was to investigate the level of IL- 6 and whether it is associated with exacerbation frequency in a subjective group that was classified in line with the latest Global Initiative for Chronic Obstructive Lung Disease through the ABCD assessment tool.

This study was a prospective comparative study that was conducted on 45 patients who attended to outpatient clinic and inpatients of Chest Department at BeniSuef University Hospital in the period from March 2020 to November 2020 complaining of dyspnea and were 


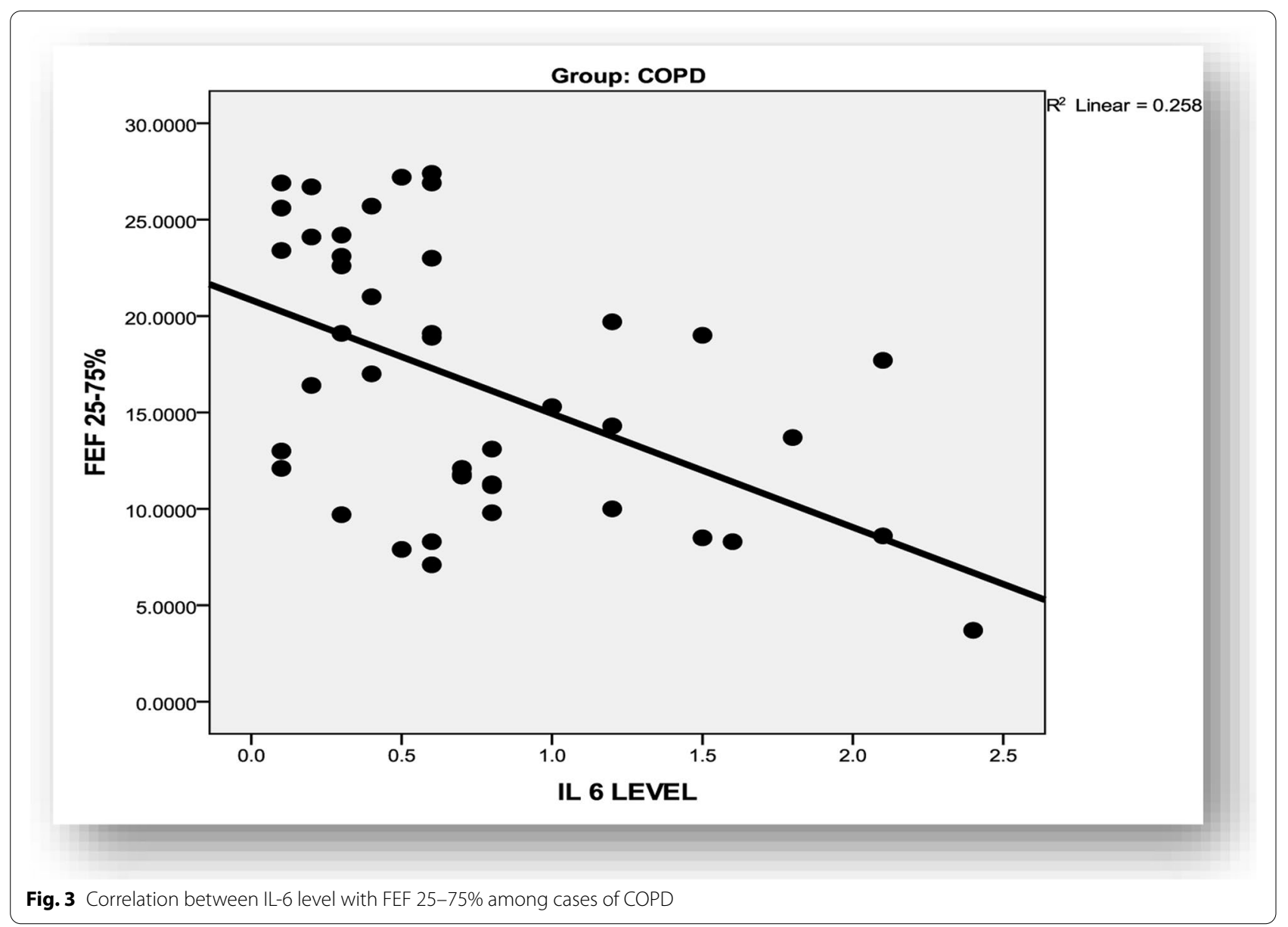

diagnosed as chronic obstructive lung disease by the Pulmonary Function Test, and 45 apparently healthy subjects as controls who were not COPD.

The demographic features of the studied groups were shown in Table 1; most of the patients were at age ranging from 51 to 78 with a mean of $61.2 \pm 7.1$ years with male predominance $(68.9 \%)$. The control group was in the six decade of their life with a mean of $62.1 \pm 7.5$ years; $57.8 \%$ were males, and $42.2 \%$ were females. López-Campos et al. [13] mentioned that the increase in age was the most prominent in middle-aged and older populations. This increase is due to longer life expectancy, which led to an increase of the number of individuals in older age groups, and continuous exposure to risk factors, which led to an increase in prevalence among the middle-aged. This agree with [14] who mentioned that the prevalence of COPD in males was much higher than that in females. The excess was most likely to be explained by historic patterns of smoking and occupational exposures in men. Our results showed that there was no statistically significant difference between cases and controls as regards demographic characters (age, and sex) with a $p$-value $>0.05$.
On the other hand, there was a statistically significant difference regarding the mean of smoking index among COPD cases with a $p$-value $<0.05$. This agrees with [15] that clearly mentioned that COPD is much more frequent in smokers than in ex-smokers. In our study, IL-6 level was higher in the case group than in the control group with a mean of $0.76 \pm 0.59$ in patients in comparison with $0.23 \pm 0.25$ in the control group, and there was a statistically significantly higher mean of IL-6 level among COPD cases with a $p$-value $<0.05$. The results were consistent with the findings of some previous studies such as [16]. It demonstrated that IL-6 blood levels were significantly elevated in patients with COPD compared to those in healthy subjects, which suggests that systemic inflammatory activity exists in stable COPD patients.

Bolton et al. [17] determined that IL-6 is increased in patients with COPD and has a role in the control of the acute inflammatory response, including regulation of the synthesis and secretion of CRP. De Moraes et al. [16] also found that a greater number of exacerbations per year may be related to systemic inflammation, and it may indicate increased inflammatory activity in these patients, 


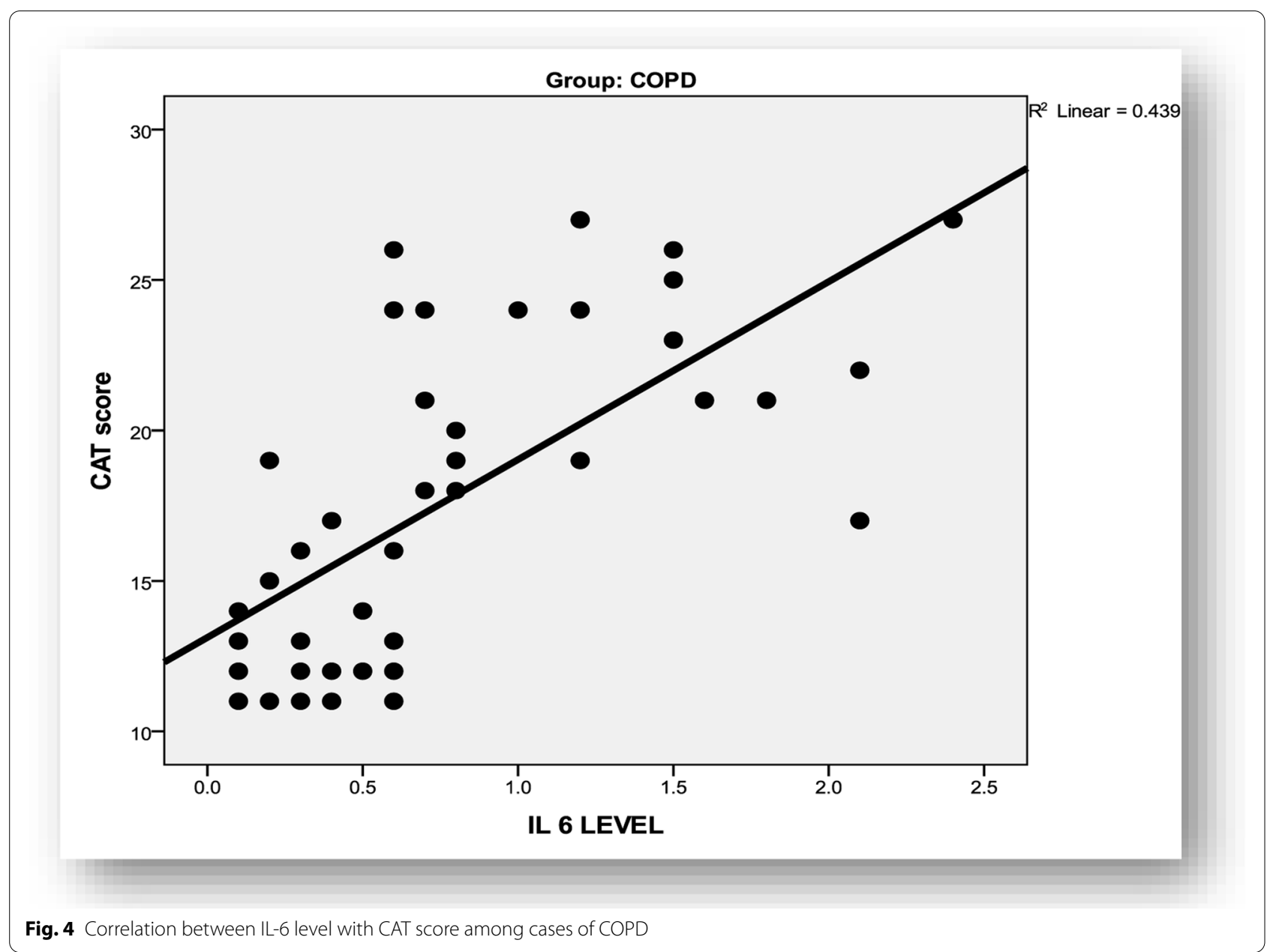

which can persist after recovery. Higher levels of IL-6 were exhibited in individuals with at least one exacerbation per year in the present study. Patients with more than 2.5 exacerbations per year exhibited an increase in IL-6 that was related to a more rapid loss of FEV1. These exacerbations are important in COPD progression, but this disease's mechanisms are not fully understood. Several recent studies have investigated the inflammation in COPD and the possible mechanisms of its systemic effects. In agreement with previous studies, Foschino Barbaro et al. [18] found significant increases in several inflammatory biomarkers (CRP, TNF-u, IL-6) and leukocytesin in the peripheral blood of a group of ex-smoker COPD patients compared to age-matched healthy subjects. A study by [19] showed no significant difference in the values of IL- 6 between patients and controls which differed from our result. Likewise, Van Helvoort et al. [20] also reported similar results that inflammatory values did not reach significance between muscle-wasted and non-muscle-wasted patients. Obvious heterogeneity was observed in the comparison of our study which might be explained by the methodological differences among those primary studies, especially gender differences and different disease severities in the included population.

In the present study, a significant decrease was found in the pulmonary functions of severe COPD patients when compared with mild and moderate COPD patients and controls; the findings of the present work are consistent with those of many authors who found that pulmonary function data (FEV1, FVC, FEV1\%) were significantly lower in COPD patients when compared with controls [21]. The extent of inflammation, fibrosis, and luminal exudates in the small airways is correlated with the reduction in FEV1 and FEV1\%. The airflow limitation in COPD patients is due to the increase in the resistance to airflow, which is caused by smooth muscle hypertrophy, goblet cell metaplasia, degeneration of the airway cartilage, and mucous hypersecretion [22].

In the present study, serum IL-6 was significantly higher in severe than in mild and moderate COPD patients and control participants. The results of this 


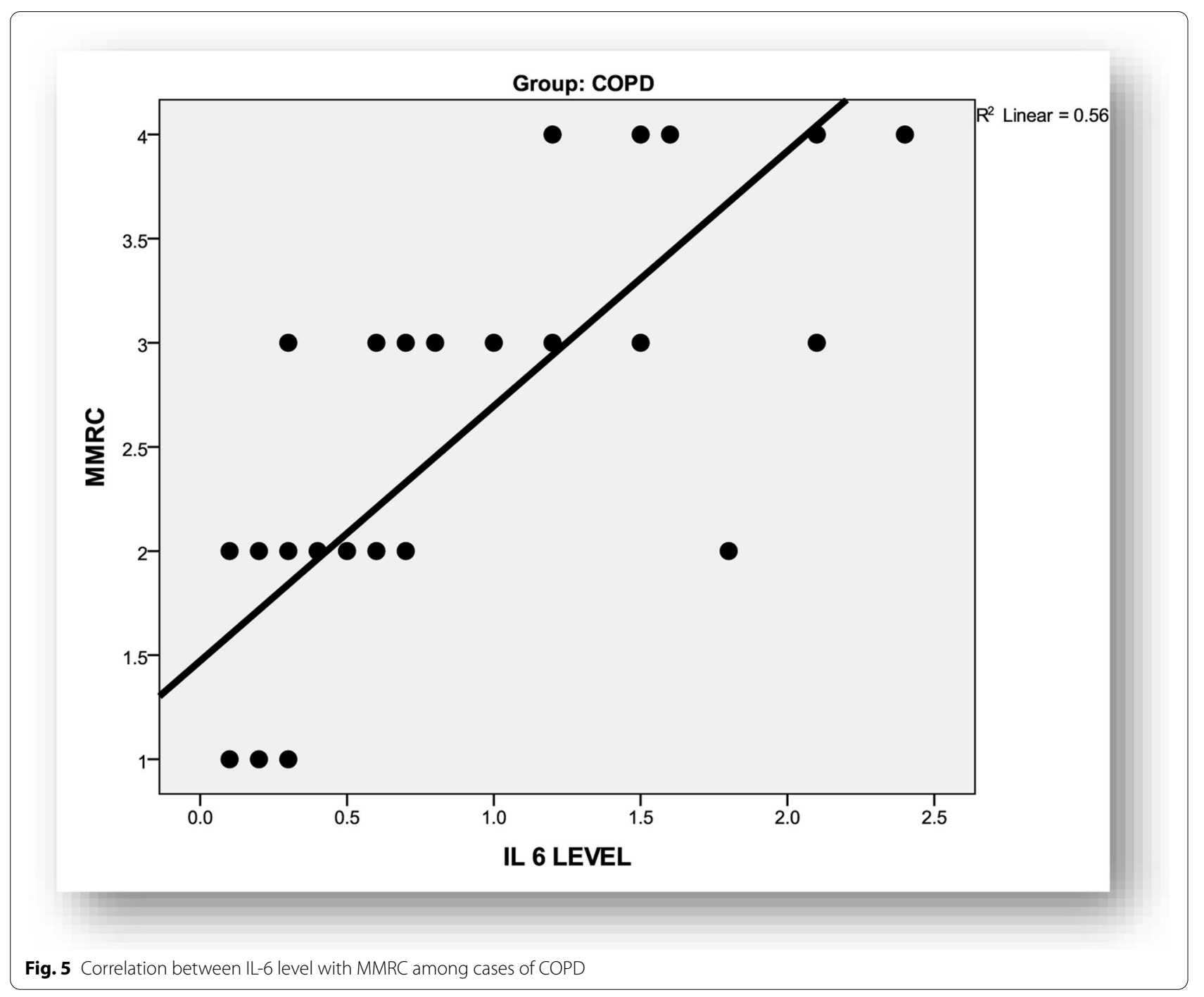

work are consistent with the study of [23] who found that serum IL-6 increases during COPD exacerbation compared with stable COPD patients and healthy controls, as they investigated both fibrinogen and IL- 6 that are acutephase proteins and have been shown to rise acutely at COPD exacerbation. IL-6 was higher during viral exacerbations than during exacerbations in which viruses were not detected. Plasma fibrinogen is synthesized in the liver in increased amounts during the acute-phase response, and this is mediated by the cytokine IL- 6 . Respiratory virus infection can increase IL- 6 production by blood monocytes and thus increase the plasma fibrinogen levels. Arschang et al. [24] assess the circulating levels of vascular endothelial growth factor (VEGF) and markers of systemic inflammation, IL-6, and TNF- $\alpha$ in patients with stable and exacerbated COPD, and they found that patients with acute exacerbated COPD had higher circulating concentrations of VEGF $(p<0.001)$, IL-6 ( $p$ $<0.05)$, and CRP $(p<0.01)$ and an increased blood neutrophil cell count $(p<0.05)$ compared with patients with stable COPD and healthy controls. VEGF levels in exacerbated COPD correlated with systemic inflammatory markers, such as CRP $(r=0.61, p<0.005)$, IL-6 $(r=0.46$; $p<0.01)$, and fibrinogen $(r=0.39, p<0.05)$. Also, the results of this study agree with [25] and [26] who found that the concentrations of circulating serum IL- 6 were significantly higher in patients with COPD in comparison with control participants, and their levels increased according to the stage of the disease. Our results also agree with the study of [27], which included 2164 COPD patients and 245 healthy controls who had been followed for 3 years, and they found that the circulating IL-6 levels were significantly higher in individuals with COPD when compared with controls. Regarding the relationship 


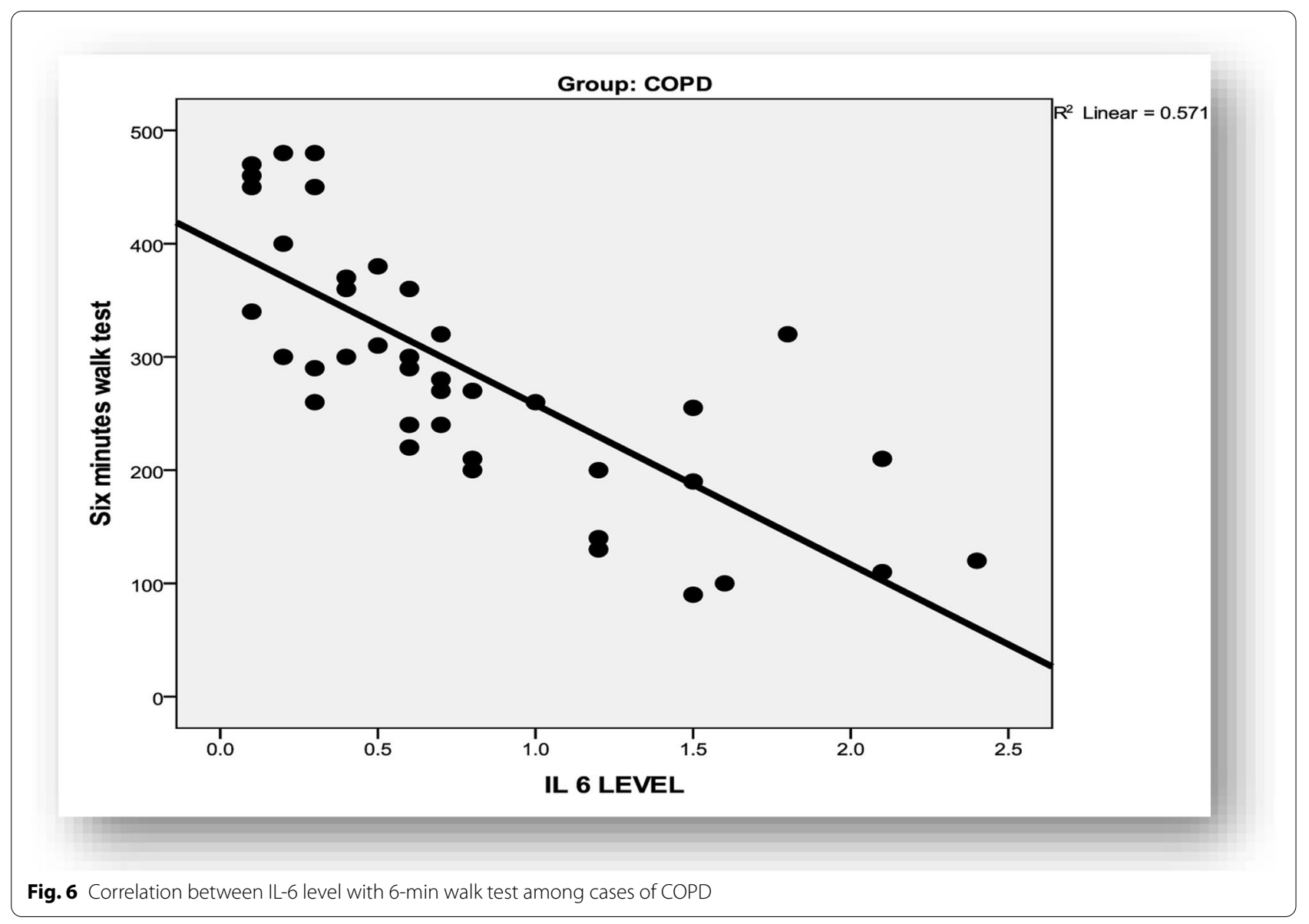

between serum IL-6 and spirometry findings, our study demonstrated that there was a significant negative correlation between IL-6 serum level and FEV1\%, FVC\%, and MEF25-75\% predicted values. This agree with [28] found a negative significant correlation between IL- 6 levels and FEV1\%.

In our study, we used IL-6 levels combined with CAT scores to determine the risk stratification of AECOPD patients during emergency visits. We found that the CAT score in the patient group significantly increased at the time of consultation compared with the control group. Some previous indicators like white blood cell counts and lung function were regarded as "gold standard" for the diagnosis and evaluation of COPD patients' conditions, but they cannot fully reflect the overall physical function of patients with COPD. The sensitivity of the CAT score in assessing changes in the patient's condition is higher than that of the lung function tests, which provides a more convenient evaluation index for clinicians to judge the development of COPD in a timely and accurate manner [29].

In this study, the CAT score was used to evaluate the patients with emergency AECOPD within $48 \mathrm{~h}$, and it was found to have clinical predictive value. We found that the blood concentration of IL- 6 in the patient group was significantly higher than that in the control group, indicating the systemic inflammatory response in the patient group was significantly worse than that of the control group. Studies have shown that the increase of serum IL-6 levels in AECOPD patients not only represents the body's defense against infection, but also can be used as an indicator of early inflammation in infection, which is significantly increased in acute inflammatory reactions [30]. Chen et al. [31] believed that IL- 6 was the best systemic inflammatory cytokine to reflect the dyspnea and pulmonary function. In this study, we found that there was a significant difference in the concentration of IL-6 between the two groups. However, there were no significant differences between the white blood cell count, which supported that IL- 6 has certain advantages in the early prediction of AECOPD patients' condition. In this study, the IL-6 level was used to evaluate patients with emergency AECOPD within $48 \mathrm{~h}$. Thus, the combined use of CAT scores and IL- 6 levels presented a significant increase in the prediction accuracy of patients with emergency AECOPD. 
The walking test is another important clinical marker that is routinely used in COPD patients to assess mortality risk and the capacity to perform daily living activities. Morales et al. [32] related IL-6 levels to more exacerbations during the previous year and higher degrees of dyspnea on the 6MWT, but not with the distance walked. In the present study, a statistically significant negative correlation with a $p$-value $<0.05$ between level of IL-6 and 6-min walk test among cases with COPD, which indicated decrease 6-min walk test, will associate with the increase in IL-6 level. Dyspnea, as measured by mMRC, is a BODE index parameter that is used to determine COPD severity according to the GOLD criteria (2011). Aaron et al. [33] demonstrated that CRP, IL-6, and IL-8 are significantly associated with worsening dyspnea. This finding agrees with our results that showed a statistically significant positive correlation with a $p$-value $<0.05$ between the level of IL- 6 and MMRC among cases with COPD, which indicated that decrease in MMRC will associate with the decrease in IL-6 level. In our study, there was a statistical significant higher mean of IL- 6 level among COPD cases who show exacerbation frequency with a $p$-value $<0.05$. This agrees with [34] showing that the annual rate of exacerbations during the 3 -year follow-up was higher in the persistently inflamed patients, compared with non-inflamed patients. However, the logistic regression did not show an association between that annual rate of exacerbations and the presence of persistent systemic inflammation (defined as in upper quartile at baseline and after 1-year for at least 2 biomarkers).

\section{Conclusion}

The study revealed that serum IL-6 level elevated with increasing severity of airflow limitation in COPD patients, particularly in the acute exacerbation phase. This increase was associated with a reduced quality of life and increased severity of hypoxemia.

\section{Abbreviations \\ AECOPD: Acute exacerbation of chronic obstructive pulmonary disease; GOLD: Global Initiative for Chronic Obstructive Lung Disease; CAT: COPD Assessment Test; CRP: C-reactive protein; IL-6: Interleukin-6; FEV1: Forced expired volume in 1 s; FVC: Forced vital capacity; MMRC: Modified Medical Research Council; MEF: Mid-expiratory flow.}

\section{Acknowledgements}

NA.

\section{Authors' contributions}

RM conceived the publication design and prepared the manuscript. FH collected the patients' data and performed the statistical component. LA revised the methods and results. RK performed the laboratory studies. All authors have read and approved the final manuscript.
Funding

Nil.

Availability of data and materials

Not applicable.

\section{Declarations}

Ethics approval and consent to participate

The study conforms to the ethical standards of the Helsinki Declaration, and a written informed consent was obtained from either the patients themselves or their relatives, and approval was obtained from the hospital's research ethics board of Beni-Suef University Faculty of Medicine. ClinicalTrial.gov: NCT05214508

Consent for publication

Not applicable.

\section{Competing interests}

The authors declare that they have no competing interests.

\section{Author details}

${ }^{1}$ Chest Diseases, Faculty of Medicine, Beni-Suef University, Beni-Suef, Egypt.

${ }^{2}$ Clinical Pathology, Faculty of Medicine, Beni-Suef University, Beni-Suef, Egypt.

Received: 5 October 2021 Accepted: 5 February 2022

Published online: 19 February 2022

\section{References}

1. Global Initiative for Chronic Obstructive Lung Disease (GOLD) (2019) Global strategy for the diagnosis, management, and prevention of chronic obstructive pulmonary disease 2019 report. Https://goldcopd. org/wp-content/uploads/2018/11/GOLD-2019-v1.7-FINAL14Nov2018WMS.pdf.

2. Guerreiro I, Soccal PM (2019) Les phénotypes de la BPCO [COPD and phenotypes]. Rev Med Suisse 15(671):2082-2086

3. Solleiro-Villavicencio H, Quintana-Carrillo R, Falfán-Valencia R, VargasRojas MI (2015) Chronic obstructive pulmonary disease induced by exposure to biomass smoke is associated with a Th2 cytokine production profile. Clin Immunol 161(2):150-155

4. Scheller J, Garbers C, Rose-John S (2014) Interleukin-6: from basic biology to selective blockade of pro-inflammatory activities. Semin Immunol 26:2-12

5. Stephan B, Rudolf AJ, Michael P (2008) Treatment of respiratory failure in COPD. Int J Chron Obstruct Pulmon Dis 3(4):605-618

6. Barnes PJ, Di Shapiro S, Pauwels RA (2003) Chronic obstructive pulmonary disease: molecular and cellular mechanisms. Eur Respir J 22:672-688

7. Hogg JC, Chu F, Utokaparch S, Woods R, Elliott WM, Buzatu L, Cherniack RM, Rogers RM, Sciurba FC, Coxson HO, Pare PD (2004) The nature of small-airway obstruction in chronic obstructive pulmonary disease. N Engl J Med 350:2645-2653

8. Gan WQ, Man SF, Senthilselvan A, Sin DD (2004) Association between chronic obstructive pulmonary disease and systemic inflammation: a systematic review and a meta-analysis. Thorax. 59:574-580

9. Rosenberg SR, Kalhan R (2012) Biomarkers in chronic obstructive pulmonary disease. Transl Res 159:228-237

10. Heinrich PC, Castell JV, Andus T (1990) Interleukin-6 and the acute phase response. Biochem J 265:621

11. Garcia-Rio F, Miravitlles M, Soriano JB, Munoz L, Duran-Tauleria E, Sanchez G, Sobradillo V, Ancochea J (2010) Systemic inflammation in chronic obstructive pulmonary disease: a population-based study. Respir Res 11:63-77

12. Bai P, Sun Y, Jin J, Hou J, Li R, Zhang Q, Wang Y (2011) Disturbance of the OPG/RANK/RANKL pathway and systemic inflammation in COPD patients with emphysema and osteoporosis. Respir Res 12:157-164

13. López-Campos JL, Tan W, Soriano JB (2016) Global burden of COPD. Respirology. 21:14-23 
14. Adeloye D, Chua S, Lee C, Basquill C, Papana A, Theodoratou E, Nair H, Gasevic D, Sridhar D, Campbell H, Chan KY (2015) Global and regional estimates of COPD prevalence: systematic review and meta-analysis. J Glob Health 5:020415

15. Rossi A, Butorac-Petanjek B, Chilosi M, Cosio BG, Flezar M, Koulouris N, Marin J, Miculinic N, Polese G, Samaržija M, Skrgat S (2017) Chronic obstructive pulmonary disease with mild airflow limitation: current knowledge and proposal for future research-a consensus document from six scientific societies. Int J Chron Obstruct Pulmon Dis 12:2593-2610

16. De Moraes MR, Da Costa AC, Correa K d S, Junqueira-Kipnis AP, Rabahi MF (2014) Interleukin-6 and interleukin-8 blood levels' poor association with the severity and clinical profile of ex-smokers with COPD. Int J Chron Obstruct Pulmon Dis 9:735-743

17. Bolton CE, Broekhuizen R, lonescu AA, Nixon LS, Wouters EF, Shale DJ, Schols AM (2007) Cellular protein breakdown and systemic inflammation are unaffected by pulmonary rehabilitation in COPD. Thorax. 62:109-114

18. Foschino Barbaro MP, Carpagnano GE, Spanevello A, Cagnazzo MG, Barnes PJ (2007) Inflammation, oxidative stress and systemic effects in mild chronic obstructive pulmonary disease. Int J Immunopathol Pharmacol 20:753-763

19. Oncel C, Baser S, Cam M, Akdag B, Taspinar B, Evyapan F (2010) Peripheral neuropathy in chronic obstructive pulmonary disease. COPD. 7:11-16

20. Van Helvoort HA, Heijdra YF, Thijs HM, Vina J, Wanten GJ, Dekhuijzen PN (2006) Exercise-induced systemic effects in muscle-wasted patients with COPD. Med Sci Sports Exerc 38:1543-1552

21. James A, Palmer L, Kicic E (2005) Decline in lung function in the Busselton Health Study. Am J Respir Crit Care Med 171:109-114

22. Haraguchi M, Shimura S, Shirato K (1999) Morphometric analysis of bronchial cartilage in chronic obstructive pulmonary disease and bronchial asthma. Am J Respir Crit Care Med 159:1005-1013

23. Seemungal T, Harper-Owen R, Bhowmik A, Moric I, Sanderson G, Message S, MacCALLUM PE, Meade TW, Jeffries DJ, Johnston SL, Wedzicha JA (2001) Respiratory viruses, symptoms, and inflammatory markers in acute exacerbations and stable chronic obstructive pulmonary disease. Am J Respir Crit Care Med 164:1618-1623

24. Valipour A, Schreder M, Wolzt M, Saliba S, Kapiotis S, Eickhoff P, Burghuber OC (2008) Circulating vascular endothelial growth factor and systemic inflammatory markers in patients with stable and exacerbated chronic obstructive pulmonary disease. Clin Sci 115:225-232

25. Attaran D, Lari SM, Towhidi M, Marallu HG, Ayatollahi H, Khajehdaluee M, Ghanei M, Basiri R (2010) Interleukin-6 and airflow limitation in chemical warfare patients with chronic obstructive pulmonary disease. Int J Chron Obstruct Pulmon Dis 5:1-6

26. Abd El-Maksoud MD, Samy N, EL Khayyal A (2010) Clinical utility of biomarkers as predictors of lung function in chronic obstructive pulmonary disease. NY Sci J 3:25-32

27. Celli BR, Locantore N, Yates J, Tal-Singer R, Miller BE, Bakke P, Calverley P, Coxson H, Crim C, Edwards LD, Lomas DA (2012) Inflammatory biomarkers improve clinical prediction of mortality in chronic obstructive pulmonary disease. Am J Respir Crit Care Med 185:1065-1072

28. Soler N, Ewig S, Torres A, Filella X, Gonzalez J, Zaubet A (1999) Airway inflammation and bronchial microbial patterns in patients with stable chronic obstructive pulmonary disease. Eur Respir J 14:1015-1022

29. Chhabra SK, Dash DJ (2014) Acute exacerbations of chronic obstructive pulmonary disease: causes and impacts. Indian J Chest Dis AlliedSci 56(2):93-104

30. Oh JY, Lee YS, Min KH, Hur GY, Lee SY, Kang KH, Rhee CK, Park SJ, Shim JJ (2018) Difference in systemic inflammation and predictors of acute exacerbation between smoking-associated COPD and tuberculosis-associated COPD. Int J Chron Obstruct Pulmon Dis 13:3381-3387

31. Chen CZ, Ou CY, Hsu CH, Hsiue TR (2015) Validation of the GOLD 2013 classification in predicting exacerbations and mortality in Taiwanese patients with chronic obstructive pulmonary disease. J Formos Med Assoc 114:1258-1266

32. Morales SA, Dreyse DJ, Díaz PO, Saldías PF, Carrasco M, Lisboa BC (2010) Systemic inflammation among stable ex smokers with chronic obstructive pulmonary disease. Rev Med Chil 138(8):957-964

33. Aaron SD, Vandemheen KL, Ramsay T, Zhang C, Avnur Z, Nikolcheva T, Quinn A (2010) Multi analyte profiling and variability of inflammatory markers in blood and induced sputum in patients with stable COPD. Respir Res 11:4

34. Agustí García-Navarro À, Edwards LD, Rennard SI, MacNee W, Tal-Singer R, Miller BE, Vestbo J, Lomas DA, Calverley PM, Wouters E, Crim C (2012) Persistent systemic inflamation is associated with poor clinical outcomes in COPD: a novel phenotype. PLoS One:e37483. https://doi.org/10.1371/ journal.pone.0037483

\section{Publisher's Note}

Springer Nature remains neutral with regard to jurisdictional claims in published maps and institutional affiliations.

\section{Submit your manuscript to a SpringerOpen ${ }^{\circ}$ journal and benefit from:}

- Convenient online submission

- Rigorous peer review

- Open access: articles freely available online

- High visibility within the field

- Retaining the copyright to your article

Submit your next manuscript at $\boldsymbol{\nabla}$ springeropen.com 